\title{
Efeito da idade sobre a qualidade de vida e saúde dos catadores de materiais recicláveis de uma associação em Governador Valadares, Minas Gerais, Brasil
}

\author{
Age effect on the life quality and health of garbage collectors of \\ an association in Governador Valadares, M inas Gerais State, Brazil
}

Jane Rabelo Almeida ${ }^{1}$

Elcinéia Tavares Elias ${ }^{2}$

$M$ arcos Alves de $M$ agalhães ${ }^{2}$

Antônio José Dias Vieira ${ }^{3}$

\footnotetext{
${ }^{1}$ Departamento de Enfermagem, Universidade PresidenteAntônio Carlos. Rua M anoel Byrro 241, Vila Bretas. 35032-620 Governador Valadares M G. jra_bio@yahoo.com.br

${ }^{2}$ Centro Universitário de Caratinga.

${ }^{3}$ Instituto Federal de Educação, Ciênciae Tecnologia do M aranhão.
}

Abstract Workers that segregate recyclable garbage are daily exposed to unhealthy work conditions which can have a more intense negative effect with aging of the garbage collector. A population of garbage collectors from Governador Valadares, M inas Gerais, Brazil answered a semi- structured questionnaire regarding the presence or $a b-$ sence of labor pain, pain intensity, living conditions, access to health services, occurrence of accidents at works and degree of personal satisfaction. These variables were correlated with the age of the workers. It was observed that pain is not associated to age increase and that it doesn't affect the degree of personal satisfaction of thestudied population. The education degree was negatively related with age. The youngest garbage collectors presented a lower degree of life satisfaction. Theage of the workers doesn't have any association with the occurrence of accidents at work and dwelling type. Key words Labor, Age, Life quality, Personal satisfaction
Resumo Trabalhadores que segregam materiais recicláveis são expostos diariamente a condições insalubres de trabalho que podem afetar com mais intensidade sua saúde em função do aumento de idade cronológica. U ma população de catadores de materiais recicláveis na cidade de Governador Valadares, M inas Gerais, Brasil respondeu a um questionário semi-estruturado que continha questões sobre a presença e/ou ausência de dor laboral, intensidadeda dor, moradia, acesso a serviços de saúde, presença ou ausência de acidentes laborais e grau de satisfação pessoal. Essas variáveis dependentes foram correlacionadas com a variável independenteidade do trabalhador. O bservou-sequea dor não está associada ao aumento da idade enão interfereno grau desatisfação pessoal da população estudada. 0 grau de escolaridade teve associação negativa com a idade. Os catadores mais jovens apresentaram menor grau de satisfação pela vida. A idade não tem nenhuma associação com a ocorrência de acidentes laborais e tipo de moradia. Palavras-chave Trabalho, Idade, Qualidade de vida, Satisfação pessoal 
Introdução

0 estudo foi realizado na cidade de Governador Valadares, localizada no leste mineiro, a 324 quilômetros de Belo Horizonte. É uma cidade de mé dio porte, com população urbana estimada em 2006 de 286.612 habitantes $^{1}$ habitantes, esegundo o censo de 2000, 22,4\% desua população urbana encontram-se na faixa etária entre 18 e 29 anose $40,1 \%$, entre 30 e 74 anos$^{2}$. Como todo centro urbano em expansão, apresenta uma série de problemas ambientais e sociais; dentre eles, destacam-se o aumento na geração de resíduos sólidos urbanos (RSU) e a falta de opção de trabalho.

Se por um lado o aumento na geração de resíduos se constitui em problema, em muitas localidades, devido à falta de opção de trabalho, torna-se uma fonte alternativa de renda, possibilitando a sobrevivência para muitas pessoas excluídas socialmente que vivem da catação de materiais recicláveis segregados do lixo.

A falta de oportunidade de trabalho tem le vado muitas pessoas no Brasil a se transformarem em catadores de lixo como forma de garantir a sobrevivência?. Há anos, a indústria de reciclagem no Brasil é "sustentada" pela catação informal de materiais encontrados nas ruas e lixões. As condições de trabalho, embora extre mamente insalubres, proporcionam para esses catadores uma liberdade no horário de trabal ho e de comportamento inexistente em empregos fixos ${ }^{4}$, razão pela qual muitos catadores recusam oportunidades de empregos, preferindo as atividades de segregação de materiais recicláveis.

$\mathrm{Na}$ cidade de Governador Valadares, há uma associação de catadores de materiais recicláveis formada quase na totalidade por ex-catadores do antigo "lixão". São 67 trabalhadores que, até pouco tempo, cerca de cinco anos atrás, viviam marginalizados, em condição degradante, catando lixo nas ruas ou no lixão e, atualmente, trabaIham de forma organizada e podem ser reconhecidos por parte da população como agentes de preservação ambiental. Entender a importância da reciclagem é o primei ro passo, mas saber praticá-la é o desafio maior. Um projeto de reciclagem bem gerenciado pode apresentar resultados positivos surpreendentes. ${ }^{5}$.

Para se avaliar a qualidade de vida dos catadores, foi usado o conceito adotado pela Organização M undial deSaúde(OM S) em 19486: "Saúde é o estado de completo bem estar físico, mental e social e não apenas a ausência de doença" ${ }^{\prime \prime}$. Com base nesse conceito, foi avaliado, sob a ótica dos catadores, o nível de percepção de bem-estar físi$\mathrm{co}$, mental e social relacionado à atividade por eles desenvolvida. Por setratar decomplexo esubjetivo, deve-se considerar os aspectos individuais físicos, emocionais e sociais etambém de percepção, isto é, o modo como a pessoa se vê em relação à vida. Avaliar o nível de qualidade de vida representa verificar como o indivíduo se senteem relação às suas aptidões física, emocional esocial, ao trabalho e ao estilo de vida ${ }^{6}$.

Relacionar as esperanças e expectativas de vida com o contexto no qual se vive é uma das ferramentas para avaliar a qualidade de vida; se as diferenças entreesperanças e expectativas são grandes, pressupõe-se que qualidade de vida seja baixa.

O patamar material mínimo para sefalar em qualidade de vida diz respeito à satisfação das necessidades mais elementares da vida humana: alimentação, acesso à água potável, habitação, trabalho, educação, saúde e lazer; elementos materiais que têm como referência noções relativas de conforto, bem-estar e realização individual e coletiva ${ }^{8}$

Nesse sentido, o trabalho é um dos meios de assegurar a satisfação das necessidades pessoais e, como tal, representa um fator determinante na qualidade de vida. 0 trabalhador deve ter assegurado o direito à "um bom ambiente de trabalho" $\mathrm{e}$ "boas condiçõesfísicas", "emocionais" e "materiais" para desempenhá-lo de "forma satisfatória".

Segundo Walton, citado por Minayo ${ }^{9}$, outro fator que pode afetar a qualidade de vida dos trabalhadores é o estresse. Além de o estresse ser fator que pode afetar a qualidade de vida dos trabalhadores, a dor também pode alterar comportamentos, provocar dificuldades no trabalho e mudanças no estilo de vida6; portanto, éum fator estressante e deve ser objeto de estudos. Segundo a Associação Internacional para o Estudo da D or, citado em Sudbrack ${ }^{10}$, a dor é uma experiência sensorial eemocional desagradável, associada a uma lesão tecidual potencial ou real, ou descrita nos termos deuma tal lesão. Esta definição[... ], submeteuse a um adendo concernente à dor crônica: "dor crônica, definida por uma duração maior que três meses, altera a personalidade do paciente, assim como sua vida familiar, social e profissional".

A dor 11 "é uma sensação desagradável, extremamente individual [...], varia conformemuitos fatores, entreeles sensibilidade, cultura, religião e até localização geográfica de cada um", e ainda, "pelo fato de ser a dor uma sensação íntima e pessoal, é impossível conhecer com exatidão a dor do outro".

A dor é o tipo de ocorrência que aniquila o bom humor de qualquer pessoa, mas também funciona como alarme, um alerta de quealgo vai mal e merece a nossa atenção; então, até certo 
ponto, a dor cumpre um papel saudável. A dor possui várias intensidades, denominadas pelo próprio indivíduo; ela pode ser ligeira, desconfortante, desolante, horrível eatroz ${ }^{11}$. A dor, além de ser consequência de um estado de estresse emocional, pode também apresentar causas físicas ou mesmo estar relacionada ao tempo de vida.

Estudo com catadores de um aterro metropolitano no Rio de Janeiro ${ }^{12}$ demonstrou que, ao serem questionados sobre sintomas de doenças que estavam sentindo no período da entrevista, $17,7 \%$ dos entrevistados citaram diferentes tipos de dor como resposta.

No início da fase adulta, as mudanças fisiológicas são muito pequenas e quase não são percebidas. Pressupõe-se que 0 que acontece com 0 corpo à medida que se envelhece influencia muito na questão da qualidade de vida versus quantidade de vida e que as condições de vida e saúde do ser humano tendem a piorar. No entanto, novas pesquisas mostram que, na idade avançada, essas mudanças, apesar de muito variáveis, nem sempre implicam deterioração do funcionamento físico e da saúde. Muito dos declínios associados com o envelhecimento podem ser mais efeitos do que causas ${ }^{13}$; segundo esse autor, estilos de vida mais saudáveis podem permitir que um número cada vez maior dejovens e adultos de meia idade mantenha um nível elevado de funcionamento físico em boa parte da terceira idade.

Como não foi feito anteriormente nenhuma avaliação das condições de trabalho e de saúde dos membros da associação de catadores de materiais recicláveis de Governador Valadares para verificar se houve melhoria em suas condições de vida após a saída do ambiente do "Iixão", pouco se sabe sobre as dificuldades e expectativas de vida desses trabalhadores.

Muitos membros de grupos minoritários, dentreesses os catadores demateriais recicláveis, que estão em envelhecimento, estão em alto risco por causa da pobreza, assi stência médica inadequada, história irregular de trabal ho e educação e tendem a ter menor nível de instrução e ren$d a^{13}$. Portanto, à medida que os catadores enveIhecem, pioram suas condições de moradia e escolaridade, ocorrendo um aumento na presença e intensidade de dor eum decréscimo na satisfação pela vida. Quando se avalia a condição de vida de pessoas de diferentes idades, poderá ser identificada uma associação negativa entre idade com indicadores de saúde e qualidade de vida.

Assim sendo, os objetivos deste trabal ho são: (i) avaliar os efei tos da idade sobre a presença ou ausência de dor, (ii) associar o efeito da idade com a intensidade da dor e, (iii) relacionar a ida- de com o tipo demoradia, nível de escolaridadee ocorrência deacidentes laborais em membros da associação de catadores de materiais recicláveis de Governador Valadares, levando em consideração a variável resposta: estado de satisfação pessoal.

\section{Métodos}

A população em estudo é composta por 67 associados cadastrados. Foi entrevistada uma amostra de 41 indivíduos com idades que variam de dezoito a 74 anos, sendo que $80,5 \%$ são do sexo feminino e $90,2 \%$ tem filhos. Foram excluídos os catadores que não concordaram em participar da pesquisa.

Os entrevistadosforam identificados pela idade real e com nomes fictícios para preservar suas identidades. Todos os catadores associados são maiores de dezoito anos. A expressão "catadores maisjovens" refere-sea opiniões deindivíduosna faixa etária dos 18 aos 30 anos (29,3\% da população), enquanto "catadores mais velhos" (70,7\% da população) refere-se a opiniões de indivíduos acima de trinta anos deidade. 0 critério usado na discussão para identificar os catadores em duas classes de idade foi pelo fato da maioria dos catadores possuir idade maior que trinta anos.

A coleta de dados foi realizada no mês de junho de2006, dentro dos limites físicos da associação. Foram entrevistados catadores cadastrados e ativos na associação que concordaram em participar da pesquisa.

$\mathrm{Na}$ fase inicial da pesquisa, a associação funcionava em dois gal pões de triagem localizados em bairros distantes um do outro. 0 estudo foi realizado no galpão que era frequentado por $89,5 \%$ dos catadores associados.

Antes de iniciar a coleta de dados, foram realizadas algumas visitas ao galpão para estabelecer uma relação de proximidade entre os catadores e o pesquisador. Em seguida, foi realizada uma reunião com os trabalhadores com o objetivo de prestar esclarecimentos sobre a pesquisa e solicitar a assinatura de um termo de consentimento livreeesclarecido.

As variáveis estudadas foram: idade, satisfação pessoal, presença ou ausência de dor, intensidadeda dor, moradia, escolaridadee acidentelaboral. 0 questionário foi composto por 34 questões objetivas e subjetivas, levantando-se informações sobre as variáveis supracitadas.

Foram analisados os efeitos da idade sobre as variáveis: presença ou ausência de dor, intensidade da dor, moradia, ocorrência de acidentes 
laborais, escolaridade e satisfação pessoal, relação entre satisfação pessoal versus presença ou ausência de dor e satisfação pessoal versus intensidade da dor. As relações entre idade versus dor, ocorrência de acidentes laborais, intensidade da dor, satisfação pessoal e moradia e a relação entre intensidade da dor versus satisfação pessoal foram testadas pelo Teste $\chi^{2}$ ao nível de $5 \%$ de probabilidade. Para avaliar a correlação linear entre idade versus escolaridade (meses) foi utilizado o teste $t$ ao nível de $5 \%$ de probabilidade.

Como a pesquisa envolveu seres humanos, 0 projeto de pesquisa e o termo de consentimento livre e esclarecido foram submetidos ao Comitê deÉtica e Pesquisa localizado no Centro Universitário de Caratinga (UNEC) e obtiveram parecer favorável.

\section{Resultados ediscussão}

Observou-se que os catadores trabalham na triagem do material oriundo da coleta sel etiva durante 7,5+Y dia-1, durante cinco dias da semana (de segunda a sexta-feira) e recebem quinzenalmente um valor proporcional ao volume de material que segregam dentro deste período. Segundo entrevista com dois coordenadores de trabaIho (M ário, 36 e Alzira, 74), o espaço para a segregação dos materiais é insuficiente, o volume do lixo égrande, pois considerando que a população valadarense ainda não está conscientizada sobre a importância da coleta seletiva, o material oriundo da mesma chega muito misturado com o lixo comum. Há um alto índice de afastamento de catadores por problemas de saúde, provocando um déficit na capacidade de trabalho da cooperativa. Segundo Alzira, falta uma melhor assistência médica e uma maior conscientização dos catadores quanto à necessidade do uso de equipamentos de proteção individual (EPI).

Pode-se observar que não existe associação entre presença ou ausência de dor com a idade do trabalhador (Tabela 1). A presença de dor foi frequente em todas as classes de idade e os catadores com idade maior que trinta anos manifestaram sentir pelo menos um tipo de dor, sendo a maior incidência de dor na cabeça, perna e coluna. Também foram relatados casos de dores em outras partes do corpo, como braço, rins, ventre, coração, joelho, ouvido, pescoço e peito.

A relação entre idade e ocorrência de acidentes não foi significativa (Tabelal), como também não foi significativo o efeito da idade sobre a frequência de respostas sobre as classes de moradia dos catadores (dados não mostrados).

$\mathrm{N}$ ão foi identificada relação entre idade e intensidade da dor (Tabela 2), bem como não foi observada relação entre intensidade de dor e 0 grau de satisfação pessoa; independente da intensidade da dor sofrida pelo catador, a mai oria dos entrevistados manifestou uma grande satisfação pela vida (Tabela 2).

No entanto, existerelação positiva entre idade e satisfação pessoal; os trabalhadores mais velhos demonstram maior grau de satisfação pela vida, enquanto os catadores mais jovens demonstraram baixa satisfação pessoal (Tabela 3).

Foi constatada uma relação negativa e significativa entre idade e escolaridade (Figura 1).

A idade média dos indivíduos da população foi de $42+15$ anos. Essa faixa de idade média dos trabalhadores insere-se na faixa etária em que, segundo o censo de 2000 , encontram-se $42,2 \%$ da população valadarense².

Tabela 1. Associações entre idade versus dor e idade versus ocorrência de acidentes dos trabalhadores de uma associação de catadores de materiais recicláveis de uma associação em Governador Valadares, M inas Gerais, Brasil.

\begin{tabular}{ccccccc}
\hline \multirow{2}{*}{ Classes de idade $\left(\right.$ anos) $^{\text {ns }}$} & \multicolumn{2}{c}{ Dor } & & \multicolumn{2}{c}{ Acidentes } \\
\cline { 2 - 3 } \cline { 5 - 6 } & Presença & Ausência & & Presença & Ausência \\
\hline 10 a 30 & 7 & 5 & & 6 & 6 \\
31 a 50 & 15 & 3 & & 9 & 9 \\
51 a 80 & 10 & 1 & & 5 & 6 \\
\hline
\end{tabular}

${ }^{\text {ns }}$ Associação não significativa ao nível de $5 \%$ de probabilidade pelo Teste $\chi 2$.

Fonte: Questionário para coleta dedados. 
Tabela 2. Associações entre intensidade da dor versus satisfação pessoal e intensidade da dor versus idade dos trabalhadores de uma asso ciação de catadores de materiais recicláveis em Governador Valadares, M inas Gerais, Brasil.

\begin{tabular}{|c|c|c|c|c|c|c|}
\hline \multirow{2}{*}{ Intensidade da dor } & \multicolumn{3}{|c|}{ Satisfação pessoal ns } & \multicolumn{3}{|c|}{ Classe de idade (anos) ${ }^{\text {ns }}$} \\
\hline & Pequena & M édia & Grande & 10 a 30 & 31 a 50 & 51 a 80 \\
\hline Dor ausente & 0 & 1 & 8 & 5 & 3 & 1 \\
\hline Fraca & 0 & 2 & 7 & 1 & 5 & 3 \\
\hline M oderada & 1 & 2 & 5 & 2 & 3 & 3 \\
\hline M uito forte & 1 & 3 & 8 & 4 & 4 & 4 \\
\hline Insuportável & 0 & 0 & 3 & 0 & 3 & 0 \\
\hline
\end{tabular}

${ }^{n}$ Associação não significativa pelo Teste $\chi 2$ ao nível de $5 \%$ de probabilidade.

Fonte: Questionário para coleta dedados.

Tabela 3. Associações entre satisfação pessoal versus idade (anos) e satisfação pessoal versus dor dos trabalhadores de uma associação de catadores de materiais recicláveis em Governador Valadares, Minas Gerais, Brasil.

\begin{tabular}{lccccccc}
\hline \multirow{2}{*}{ Grau de satisfação pessoal } & \multicolumn{3}{c}{ Classe de idade (anos) } & & & \multicolumn{2}{c}{ Dor ns } \\
\cline { 2 - 4 } & 10 a 30 & 31 a 50 & 51 a 80 & & Presença & Ausência \\
\hline Pequeno & 1 & 0 & 0 & & 2 & 0 \\
M édio & 10 & 0 & 0 & & 7 & 1 \\
Grande & 1 & 18 & 11 & 23 & 8 \\
\hline
\end{tabular}

*Associação significativa pelo Teste $\chi^{2}$ ao nível de $5 \%$ de probabilidade; ${ }^{\text {ns } A s s o c i a c ̧ a ̃ o ~ n a ̃ o ~ s i g n i f i c a t i v a ~ p e l o ~ T e s t e ~} \chi^{2}$ ao nível de $5 \%$ deprobabilidade.

Fonte: Questionário para coleta dedados.

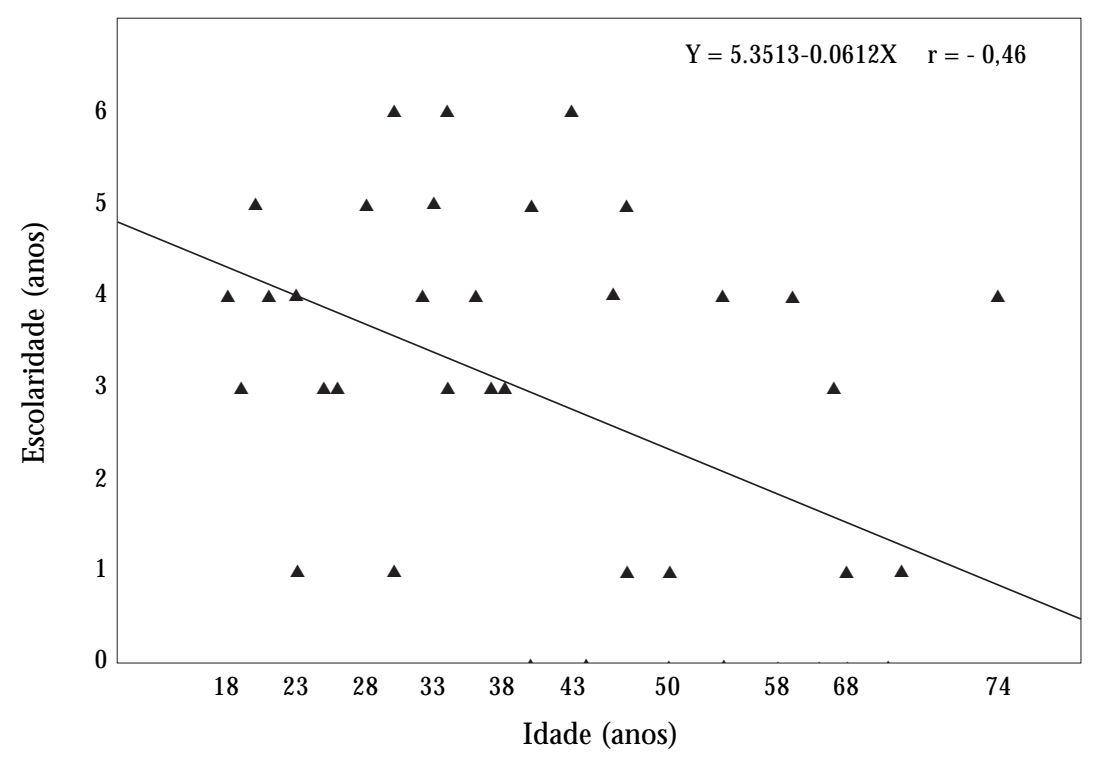

Figura 1. Correlação entre idade (anos) e escolaridade (meses) dos trabalhadores de uma associação de catadores de materiais recicláveis em Governador Valadares, M inas Gerais, Brasil.

Fonte: Questionário para coleta dedados. 
$\mathrm{Na}$ associação em estudo, observou-se que mesmo os trabalhadores com idade acima da média da população de catadores são produtivos, se envolvem com o trabalho e com a rotina das atividades. Alguns grupos de trabalhadores nesta faixa etária são muito produtivos, em parte porque tendem a ser mais conscienciosos e cuidadosos ${ }^{13}$.

A maior parte dos catadores mais jovens mostrou-se indiferente à pesquisa; alguns não quiseram responder os questionários e, quando responderam, o fizeram com descaso, externando com palavras ou gestos a descrença em algo que possa mudar sua realidade de vida. Já os catadores mais velhos se apresentaram bem cordiais, alguns aproveitaram o momento da aplicação dos questionários e falaram da importância que vêem no trabal ho, de suas conquistas e 0 valor que acreditam ter para a sociedade.

Quando os trabal hadores sentem que estão no emprego errado ou quando os esforços para atender às demandas do emprego não são proporcionais as suas recompensas (como salário, estima, oportunidade de progresso e senso de controle), o resultado pode ser o estresse, o qual apresenta como sintomas mais comuns o nervosismo, ansiedade, tensão, rai va, irritabilidade, fadiga e depressão $0^{13}$. 0 fato de participarem da pesquisa com indiferença e alguns relatos transcritos a seguir demonstram que, para os catadores mais jovens, a atividade laboral não é algo prazeroso.

Ao serem entrevistados, $16,6 \%$ dos catadores mais jovens disseram quesesentem envergonhados pelo trabalho que fazem, $50 \%$ declararam que gostariam de ter um trabalho mais seguro, ganhar bem e ter carteira assinada e 33,3\% gostariam de comer bem e ter as coisas em casa. A pesar dos catadores mais jovens possuírem um maior grau de escolaridade, uma média de três anos e sete meses de estudo, foi entre os mesmos que se percebeu um menor grau de satisfação pela vida (Tabela 3). Duranteas entrevistas, quando questionados sobre a percepção de outras pessoas sobre 0 seu trabalho, houve as seguintes respostas: "eu não sei" (Aline, 28 e Débora, 18); "muito ruim, dizem que émuito ruim eque sou muito nova para isso" (Fabrícia, 19); "é um trabalho fácil que paga pouco" (Anderson, 23); "não tenho nada para falar" (Adriana, 20 e Ana Paula,25); "esquisito por causa da pouca idade" (Poliana, 21); "alguns têm preconceito" (Jéssica, 30); somente três catadores disseram que as pessoas admiram seu trabalho. 0 catador (Tiago, 23) disse que as pessoas falam que o seu trabalho "é bom, saiu da rua"; ele foi o único catador jovem que afirmou ter uma grande satisfação pela vida, relatou que já foi usuário de drogas, vivia pela rua, mas hoje tem uma família, vive com uma mulher quetem cinco filhos eabandonou o vício para não dar "mau exemplo" às crianças queconsidera como filhos.

A educação é um processo mediante o qual as pessoas adquirem a capacidade de redefinir constantemente a qualificação necessária para uma determinada tarefa e, ainda, quem possui educação, no contexto organizativo adequado, pode reprogramar-se para as tarefas em mutação constante do processo produtivo ${ }^{14}$. Nesse sentido, corroborando com esse ponto de vista, essas demonstrações de insatisfação ficam mais evidentes nos catadores jovens provavelmente por apresentarem maior grau de escolaridade, pois a educação induz a uma exigência maior por qualidade de vida e salário. A ênfase na promoção da empregabilidade por meio da expansão de oportunidades de acesso à educação e formação assenta-se no pressuposto de que o desemprego se encontra associado a um déficit de qualificação que, sendo confrontado e resolvido, se reflete na anulação ou diminuiç̧ão desse mesmo desemprego ${ }^{14}$.

Segundo a Síntese de Indicadores Sociais de $2000^{2}$, a escolaridade média dos jovens brasileiros na faixa de 20 a 24 anos é de 7,5 anos de estudo e, com base nos dados da Síntese de Indicadores Sociais de 2004², foi esse o grupo etário queapresentou maior crescimento na frequência à escola em 2003. No entanto, essesíndices não condizem com a realidade dos jovens catadores da associação; todos abandonaram a escola e, como apresentam escolaridademédia inferior a quatro anos de estudo, são considerados analfabetos funcionais $^{2}$. De acordo com a Pesquisa Nacional por Amostra de Domicílio (2004-2005), 11,3\% da população brasileira são considerados analfabetos, pois possuem menos de um ano de estudo, $\mathrm{e}$ $14,5 \%$ são analfabetos funcionais.

Conforme o censo de 2000, 12,8\% da população valadarense adulta possuem entre um etrês anos deestudo ${ }^{2}$. N a associação em estudo, 53,6\% dos trabal hadores apresentam escolaridadeigual ou inferior a três anos de estudo; destes, 22,7\% são catadores jovens com idade inferior a trinta anos. Porém, ainda que considerado baixo, 0 aumento do nível educacional implica melhor conhecimento da realidade de vida que se distancia da realidade vivida pelos catadores mais jovens, uma vez que o mercado de trabalho écompetitivo e exige qualificação. "Os estudantes que 
deixam a escola antes de receber o diploma reduzem suas oportunidades" ${ }^{13}$ e "pessoas que abandonam a escola têm dificuldade para conseguir e manter o emprego, e os cargos conquistados tendem a ser de nível inferior e mal remunerado"13.

Com a baixa escolaridade e a falta de qualificação, as oportunidades deemprego ficam muito limitadas, acarretando desemprego, razão pela qual, segundo os entrevistados, levou os catadores a retirarem o seu sustento da catação do lixo, gerando frustração em muitos deles. 0 trabalho com a segregação do lixo é visto como o último recurso em uma sociedade marcada pela redução na oferta de empregos; enquanto outras portas se fecham ${ }^{15}$, essa é uma atividade sempre disponível. As oportunidades de obtenção de um me Ihor grau de escolaridade são remotas para muitos, pois as condições de vida não possibilitam a entrada ou a permanência por tempo significativo na escola ${ }^{15}$, a precariedade de recursos materiais, a incerteza ea pobreza dificultam a formação. Por isso, é ingenuidade alimentar expectativas de se retirar benefícios significativos da expansão de oportunidades de educação e formação, sem antes se pensar em oferecer garantias à segurança material e condições de vida dignas ${ }^{14}$.

Os catadores mais velhos apresentaram um grau de escolaridade menor, média de dois anos ecinco meses de estudo, sendo que, destes, $27,5 \%$ nunca frequentaram uma escola. No entanto, os catadores acima dos cinquenta anos, durante as entrevistas, demonstraram grande satisfação pela vida, pelo trabalho e orgulho pelo que fazem, sentem-se úteis à sociedade e ao meio ambiente, gostam de conversar e contar experiências. Enfrentam a desqualificação afirmando que o que importa é que estão trabalhando, garantindo a sobrevivên cia da família com honestidade ${ }^{15}$. Dentre os catadores entrevistados, 14,6\% relataram que estão frequentando aulas de Educação de Jovens e Adultos (EJA). A atividade mental continuada ajuda a manter o desempenho em indivíduos adultos, razão pela qual os trabal hadores mais velhos muitas vezes são mais produtivos que os mais joven $s^{13}$.

De acordo com as informações levantadas, percebeu-se que, de um modo geral, a visão dos catadores mais jovens é diferente quando comparada aos mais velhos. Os primeiros apresentam uma visão pessimista no que diz respeito às esperanças eas expectativas de vida; assim, o grau desatisfação pessoal ébaixo. Já os catadores mais velhos demonstram expectativas de vida e esperanças positivas; portanto, a qualidade de vida é satisfatória. A idade afeta a maneira como as pessoas se sentem em relação ao trabalho; pessoas com menos de quarenta anos tendem a ser menos satisfeitas com trabalho, pois consideram o trabal ho desagradável e estressante. Em contrapartida, trabalhadores com maior idade tendem a demonstrar maior satisfação, preocupamse com o tipo de trabal ho que fazem, tendem a ser mais cuidadosos, responsáveis e moderados com o tempo e com os materiais do que comparativamente os trabalhadores mais jovens ${ }^{13}$.

Ao serem abordados sobre 0 que as outras pessoas acham do seu trabalho, $69,2 \%$ dos catadores mais velhos disseram que "é bom", "importante", "bonito", "falam bem", "importante para o meio ambiente", "muito importante", "muito bom, melhor que o lixão", "gostam do meu trabalho", "importante porque contribui com a natureza". Somente oito catadores relataram o contrário: "acham queeu trabal ho no lixo" (Ana M aria, 34 e Zita,47), "não édigno" (Pedro, 50); "não é bom trabalhar com esse material" (M arizete, 59); "muito esforço, pesado (O Iga, 38); "abusam, criticam, dizem que eu trabalho com coisa suja" (Ester, 61); essa catadora tem hanseníase, está em tratamento, mas fala da doença sem problemas. A catadora (Helena, 63) disse que "as pessoas acham que esse trabalho pode trazer enfermidades"; ela demonstrou ser uma pessoa triste, disse que mora sozinha e se sente desamparada. A catadoraJoice(33) dissequenão fala com as pessoas sobre esse trabalho; ela tem um salão de beleza em casa e só trabal ha na associação para completar a renda e pagar as passagens para o filho que estuda fora, disse que sente muita vergonha "desse tipo de trabalho". No entanto, destes oito, três afirmaram que 0 grau de satisfação com a vida é médio e todos os demais afirmaram que o seu grau de satisfação com a vida é grande.

Quanto mais estressantes são as mudanças que ocorrem na vida, maior a possibilidade dese contrair doenças e esse estresse pode estar relacionado a vários fatores, dentre eles o trabalho. 0 estresse debilita o sistema imunológico, deixando a pessoa mais vulnerável a doenças como as infecções, distúrbios estomacais, depressão, insuficiência cardíaca. Pessoas sob estresse podem dormir menos, fumar e beber mais, comer mal e dar pouca atenção à saúde ${ }^{13}$.

A catadora mais jovem da associação (D ébora, 18), uma pessoa delicada, de aparência frágil e muito triste afirmou sentir muitas dores no coração, quase todos os dias e de intensidade muito forte. Demonstrou não ter interesse sobre a opinião alheia sobre o seu trabalho, afirmou 
que o seu grau de satisfação com o trabalho e com a vida são baixos e que qualidade de vida é "ganhar bem e ter o que precisa".

De acordo com os dados levantados, $78,2 \%$ dos catadores afirmaram sentir dor com intensidades variáveis entre fraca, forte, muito fortee insuportável. Destes, $37,5 \%$ sentem dor todos os dias e $21,87 \%$ sentem dor quase todos os dias. Entre os catadores mais velhos, $86,2 \%$, relataram sentir dores em pelo menos uma parte do corpo quase todos os dias. A alta prevalência de dor em pessoas mais vel has está associada a desordens crônicas, particularmente doenças musculoesqueléticas como artrites e osteoporoses ${ }^{16}$. No entanto, apesar da sensação da dor, todos os catadores foram gentis e aceitaram partici par da pesquisa com muito interesse. A catadora (Jacira, 46) estava sentindo tanta dor no momento da entrevista que não aguentou ficar sentada, relatou sentir uma dor insuportável na coluna e nos rins todos os dias; segundo a entrevistada, 0 motivo da dor seria consequência de uma queda na escada, mas afirma sentir muita satisfação pela vida e pelo trabalho.

A presença de dor pressupõe uma vida de baixa qualidade. Pode-se acreditar que níveis de dor com intensidades entre muito forte e insuportável podem afetar a qualidade de vida. A dor está entre os principais fatores que podem impactar negativamente a qualidade de vida do indivíduo idoso, pois limita suas atividades, aumenta a agitação, o risco para estresse, o isolamento social e pode resultar em depressão $0^{16}$. No entanto, os relatos dos indivíduos entrevistados contrariam essa suposição. Segundo Quirino e Xavier, citados por Filho ${ }^{6}$, uma das dificuldades para investigar a qualidade de vida nas organizações reside na "diversidade das preferências humanas e diferenças individuais dos valores pessoais e o grau de importância que cada trabalhador dá as suas necessidades [....]". Para a população em estudo, qualidade de vida implica "meIhor salário" (Mariana, 30; Luiz, 26; Leopoldo, 54); "ter condições de dar uma vida melhor para os filhos" (Jéssica, 30; Valéria, 32; M atilde, 47); "deitar sem preocupações" (M arizete, 59); "pagar as contas em dia" (Ana M aria, 34); "ter alegria e viver bem" (Alda, 50; Tiago, 23); "mais informações sobre todo tipo de assunto" (Alda, 50); "estudar" (Dulce, 44); "ter uma casa melhor" (Clara, 40); "ter uma boa alimentação e saúde" (M ônica, 28); "ter muita saúde para cuidar dos filhos" (Poliana, 21); "estar bem com os amigos, a família e consigo" (Rosa, 40); "viver em um ambiente saudável" (Ana Paula, 25); "trabalhar e ter amizade com Deus" (Francisco, 54); "não ter vicio" (M ário, 36); "ter tranquilidade" (Rute, 62); "ter uma casa com banheiro" (Augusta, 58); "ter um trabalho melhor" (Fabrícia, 19; Anderson, 23; Pedro, 50), dentre outros.

A saúde é produto de alguns fatores relacionados com a qualidade de vida, incluindo um padrão adequado de alimentação e nutrição, e de habitação e saneamento; boas condições de trabalho; oportunidades de educação; ambiente físico limpo; apoio social para famílias e indivíduos; estilo de vida responsável e cuidados de saúde $^{17}$. No entanto, para os catadores da associação em estudo, o conceito de saúde não contempla todos esses fatores, se limita a atender as suas necessidades eansei os para se sentirem bem como: "não sentir dor, não sentir nada" (M ariana, 30; Valéria, 32; Dorcas, 63); "não precisar de hospital ou demédico" (Francisco, 54); "não precisar de remédios" (Jéssica, 30; Joice, 33); "alimentar bem" (M arizete, 59; Ana Paula, 25); "não ter vício" (O Iga, 38); "estar bem com a vida" (Dé bora, 18); "conseguir trabalhar" (Zita, 47); "levantar com coragem para trabalhar" (Fabrícia, 19); "trabalhar feliz" (Alda, 50); "deitar bem e levantar sem dor", pois tem dificuldade para levantar por causa das dores que sente (Leopoldo,54); "ter higienee casa limpa” (Clara, 40); "não comer coisas que fazem mal" (Pedro, 50; Alzira, 74); "ter disposição, ser robusta" (M irtes, 32); "ter ânimo" (M ário, 36); "ser forte e animada" (Éster, 61); "acordar de bem com a vida, al egree sem febre" (M ônica, 28); "ser normal e não ter nada nos exames" (Dulce, 44).

A pesar do contato direto com o lixo, 63,4\% dos trabalhadores disseram não sentir nenhum tipo de incômodo com o cheiro do lixo; segundo eles, "a gente acaba acostumando". Através da observação direta do pesquisador, foi detectado que muitos catadores retiram do lixo roupas, eletrodomésticos, utensílios para uso pessoal e para casa e também restos de alimentos. No entanto, em conversa informal, os trabalhadores negaram o fato de recolherem alimento do lixo. Contudo, ocorreram vários flagrantes desse tipo de conduta. Quando questionados sobre o funcionamento do intestino, 78\% dos entrevistados afirmaram que sempre $o$ intestino funciona regularmente e se sentem enjôo, 70,7\% afirmaram que nunca sentem enjôos.

As condições de trabalho dos catadores são caracterizadas como extremamente insalubres ${ }^{4}$, pois as pessoas são expostas ao contato direto com materiais perfurocortantes, insetos, baratas, ratos e outros agentes contaminantes, além de outros 
vetores de inúmeras doenças. Estima-se que 30\% dos danos à saúde estão relacionados aos fatores ambientais decorrentes de inadequação do saneamento básico (água, lixo, esgoto), poluição atmosférica, exposição a substâncias químicas e físicas, desastres naturais, fatores biológicos (vetores, hospedeiros e reservatórios), dentre outros ${ }^{7}$. Os seres vivos que utilizam o lixo ainda que por curtos períodos desuas vidas, ao saírem dos lixões, acabam atuando como vetores de doenças; isso inclui 0 próprio homem ${ }^{18}$. Contudo, $73,1 \%$ dos entrevistados se consideram com saúde, o queé ratificado com conceito deque: "Saúdeéo estado decompleto bem estar físico, mental e social e não apenas a ausência de doença"7.

A promoção da saúde consiste nas atividades dirigi dasà transformação dos comportamentos dos indivíduos, focando nos seus estilos de vida e localizando-os no seio das famílias e, no máximo, no ambiente das culturas da comunidade em que se encontram ${ }^{17}$. N esse sentido, cabe uma discussão sobre os motivos que levam a ocorrência de acidentes laborais. Os dados confirmam que os acidentes são comuns com os catadores, $90,3 \%$ dos catadores declararam encontrar objetos perfurocortantes no material que segregam e $43,9 \%$ declararam que já sofreram acidentes com esses materiais, alguns por mais de uma vez, $12,1 \%$ já sofreram acidente de outra natureza e 63,4\% já presenciaram pelo menos um tipo de acidente sofrido por um colega de trabalho (Tabela 4).

Segundo entrevista com os coordenadores da associação, "todos" os catadores têm acesso aos EPI (luvas, botas, máscaras e aventais); porém, não querem utilizá-los e não há exigência por parte da coordenação nesse sentido. Uma catadora pediu para registrar que, no início das ativi-

Tabela 4. Tipos de acidentes mais comuns sofridos ou presenciados pelos trabalhadores de uma associação de catadores de materiais recicláveis em Governador Valadares, M inas Gerais, Brasil.

\begin{tabular}{lcc}
\hline Tipo de acidente & $\begin{array}{c}\text { Sofrido } \\
\text { (número) }\end{array}$ & $\begin{array}{c}\text { Presenciado } \\
\text { (número) }\end{array}$ \\
\hline corte com vidro & 15 & 19 \\
furo com prego & 2 & 12 \\
furo com agulha & 1 & 0 \\
picada ou mordida de animal & 2 & 2 \\
prensa & 2 & 4 \\
outros & 3 & 1 \\
\hline
\end{tabular}

Fonte: Questionário para coleta dedados. dades da associação, todos receberam EPI, ela rejeitou, não tem enão usa porque não quer. Um catador afirmou que não tem e não gosta de utilizar EPI; no entanto, no dia seguinte, trabalhou de bota e avental. Dentre os entrevistados, 14,6\% possuem eutilizam EPI.

Quando questionados sobre os motivos dos acidentes laborais, os catadores responderam: falta de atenção (46,3\%); falta do uso de EPI $(17,1 \%)$; materiais misturados (vidros, latas, agulhas, e outros - 17,1\%); outros (descuido ao puxar as bolsas utilizadas para colocar o material segregado; brigas; uso incorreto de equipamentos; susto com animais como ratos, escorpiões, cobras e outros; aborrecimentos com problemas pessoais ou com o trabalho e colegas - $14,7 \%$ ) e 4,8\% não sabem.

Quando se acidentam ou precisam de cuidados médicos, 75,6\% dos catadores afirmaram ter acesso a serviços de saúde; eles utilizam os serviços dos postos de saúde próximos as suas residências ou os atendimentos no pronto-socorro municipal pelo Sistema Único deSaúde(SUS). A maioria dos catadores (61\%) não se preocupa com a prevenção e manutenção da saúde, somente $39 \%$ afirmaram fazer exames médicos pelo menos uma vez ao ano e apenas $51,2 \%$ afirmaram acreditar que o trabalho com o lixo pode causar algum dano a saúde. Segundo eles, as doenças que podem ser causadas pelo contato com o lixo são: "gripe", "contaminação", "qualquer tipo de doença", "doença de pele", "dor nos ossos", "manchas na pele", "infecção", "micose", doença de lixo de hospital", "tuberculose", "febre amarela", "cortes", "dor na coluna”, "alergia”, "câncer", "doença de urina de rato" e "doença de ratos e baratas". Periodicamente, a Secretaria M unicipal de Saúde disponibiliza vacinas contra gripe, tétano, rubéola e febre amarela; no entanto, somente $65,8 \%$ dos trabalhadores afirmaram ter tomado algum tipo de vacina depois que começou a trabalhar na associação.

No aspecto relativo à escolaridade, que é um meio imprescindível eeficaz para a conscientização do ser humano quanto à valorização da própria vida e para a obtenção de informações que contribuam para melhorar sua saúde, o depoimento da catadora com maior nível de escolaridade da associação, Ana M aria (34 anos de idade, seis anos de estudo e oito anos de trabalho com a catação), destaca a importância que a mesma dá aos cuidados com a saúde: toma todas as vacinas nos períodos certos, faz exames periódicos a cada três meses e é doadora de sangue - a mesma afirmou que se orgul ha disso. No 
entanto, afirma que não utiliza EPI, não quer utilizá-los e não vê necessidade do uso para 0 tipo de trabalho que realiza. Nesse contexto, a Carta de Ottawa, elaborada na I Conferência Internacional sobre Promoção da Saúde em $1986^{19}$, descreve promoção à saúde como o processo de capacitação da comunidade para atuar na melhoria de vida e saúde, incluindo uma maior participação no controle deste processo. Para atingir um estado de completo bem- estar físico, mental e social os indivíduos e grupos devem saber identificar aspirações, satisfazer necessidades e modificar favoravelmente o meio ambiente [...]. A Saúde é o maior recurso para o desenvolvimento social, econômico e pessoal, assim como uma importante dimensão da qualidade de vida ${ }^{17}$.

\section{Conclusão}

Com base nos resultados enas condições em que foi realizada a presente pesquisa, conclui-seque: . 0 aumento da idade não é fator determinante no nível de satisfação pessoal dos catadores demateriais recicláveis;

. A presença de dor não está relacionada com a idade, bem como não foi detectada relação entre intensidade da dor e idade;

. A maioria dos catadores $(75,6 \%)$ está satisfeita com a vida, conseguiu sair de um ambiente de trabalho degradante (quase todos trabalharam anteriormente no antigo "lixão"), e tais fatores são relevantes eatribuem maior valor à vida que 0 estresse da dor;

. Existe relação positiva entre idade e satisfação pessoal; catadores mais velhos demonstram maior satisfação pessoal;

. Foi constatada uma relação negativa e significativa entre idade e escolaridade;

- Embora os acidentes laborais sejam frequentes entre a população em estudo, não existe relação positiva com aumento da idade;

. Não exister relação entre o tipo de moradia e a idade, e tipo de moradia e a satisfação pessoal;

- Faz-se necessário trabalho de capacitação dos trabalhadores da associação de catadores de materiais recicláveis de Governador Valadares, com ênfase na promoção de mudanças de comportamentos e de valorização a própria vida;

- Considerando que os catadores mais jovens demonstram menor satisfação pela vida, cabediscutir a necessidade da criação de mais oportunidades de trabal ho e de políticas públicas voltadas para qualificação e incentivo ao aproveitamento da mão-de-obra jovem. A população jovem de trabalhadores sem qualificação profissional demonstra descrédito com a vida efalta de perspectivas de melhores condições de trabalho; apesar de manifestar o interesse em ter um trabalho melhor, sentem-se excluídos socialmente.

\section{Colaboradores}

JR Almeida trabalhou no planejamento experimental, coleta e organização de dados e redação do texto; ET Elias tabulou os dados; M A M agaIhães trabalhou na revisão do texto eAJD Vieira colaborou no planejamento experimental, na redação do texto e efetuou as análises estatísticas. 


\section{Referências}

1. Wikipédia. [site da Internet]. Disponível em: http:/ /www.wikipedia.org

2. Instituto Brasileiro de Geografia e Estatística. Cidades 2000, Censo 2000, Brasil em Síntese, Síntese de Indicadores Sociais 2000 e 2004, Pesquisa Nacional por Amostra de Domicílios 2004-2005. [site da Internet]. Disponível em: http://www.ibge.gov.br

3. Magal hães $M A, M$ agalhães $A B S$, M atos AT. Levantamento e diagnóstico das condições sócio-econômicas e culturais dos catadores de lixo e do mercado de recicláveis no município de Viçosa, MG. In: II Congresso Mundial de Educação Ambiental; 2004; Rio de Janeiro.

4. D'Almeida M LO, Vilhena A. Lixo municipal: manual de gerenciamento integrado. 2a ed. São Paulo: IPT/CEM PRE; 2000.

5. Cunha FL, M elchior L. Cooperativas populares: a (re)qualificação dos catadores de resíduos sólidos recicláveis em Ourinhos e Santa Cruz do Rio Pardo. Ciência em Extensão 2005; 2:90-93.

6. Filho ACCA. Dor: diagnóstico e tratamento. São Paulo: Roca; 2001.

7. Organização Mundial de Saúde. [site da Internet]. Disponível em: http://www.who.int

8. M inayo M CS, Hartz ZM A, Buss PM. Qualidade de vida e saúde: um debate necessário. Cien Saude Colet 2000; 5:7-18.

9. Fernandes EC. Qualidade de vida no trabalho: como medir para melhorar. Salvador: Casa da Qualidade; 1996.

10. Sudbrack G. Entendendo a dor torácica. Revista AM RIGS 2002; 28-31.
11. Gusman AC, Costa DC, Bastos JC, M agalhães KS, $M$ aia LR, Pena M GM. A dor e o controle do sofrimento. Revista de Psicofisiologia 1997; 1(1):1-26.

12. Porto M FS, Junca DCM, Gonçalves RS, Filhote MIF. Lixo, trabalho e saúde: um estudo de caso com catadores em um aterro metropolitano no Rio de Janeiro, Brasil. Cad Saude Publica 2004; 20:1503-1513.

13. Papalia DE, OIds SW. Desenvolvimento humano. Porto Alegre: Artmed; 2000.

14. Afonso AJ, Antunes F. Educação, cidadania e competitividade: questões em torno de uma nova agenda. Cadernos de Pesquisa 2001; 113:83-112.

15. Paixão LP. Significado da escolarização para um grupo de catadoras de um lixão. Rev C Pesq 2005; 35:141-170.

16. Andrade FA, Pereira LV, Sousa FAEF. M ensuração da dor no idoso: uma revisão. Rev Latino-am Enfermagem 2006;14:271-276.

17. Buss PM. Promoção da saúde e qualidade de vida. Cien Saude Colet 2000; 5:163-177.

18. Ribeiro TF, Lima SC. Coleta seletiva de lixo domiciliar - estudo de casos. Caminhos de Geografia 2000:50-69.

19. Organização Pan-Americana da Saúde. [site da Internet]. Disponível em: http://www.opas.org.br

Artigo apresentado em 24/06/2007

Aprovado em 13/12/2007 